\title{
Blockade of insulin-like growth factors increases efficacy of paclitaxel in metastatic breast cancer
}

\author{
Lucy Ireland ${ }^{1} \cdot$ Almudena Santos $^{1} \cdot$ Fiona Campbell $^{1}$ - Carlos Figueiredo ${ }^{1} \cdot$ Dean Hammond $^{2} \cdot$ Lesley G. Ellies $^{3}$. \\ Ulrike Weyer-Czernilofsky ${ }^{4} \cdot$ Thomas Bogenrieder $^{5,6} \cdot$ Michael Schmid $^{1} \cdot$ Ainhoa Mielgo $^{1}$
}

Received: 22 July 2017 / Revised: 15 November 2017 / Accepted: 14 December 2017 / Published online: 25 January 2018

(c) The Author(s) 2018. This article is published with open access

\begin{abstract}
Breast cancer remains the leading cause of cancer death in women owing to metastasis and the development of resistance to established therapies. Macrophages are the most abundant immune cells in the breast tumor microenvironment and can both inhibit and support cancer progression. Thus, gaining a better understanding of how macrophages support cancer could lead to the development of more effective therapies. In this study, we find that breast cancer-associated macrophages express high levels of insulin-like growth factors 1 and 2 (IGFs) and are the main source of IGFs within both primary and metastatic tumors. In total, $75 \%$ of breast cancer patients show activation of insulin/IGF-1 receptor signaling and this correlates with increased macrophage infiltration and advanced tumor stage. In patients with invasive breast cancer, activation of Insulin/ IGF-1 receptors increased to $87 \%$. Blocking IGF in combination with paclitaxel, a chemotherapeutic agent commonly used to treat breast cancer, showed a significant reduction in tumor cell proliferation and lung metastasis in pre-clinical breast cancer models compared to paclitaxel monotherapy. Our findings provide the rationale for further developing the combination of paclitaxel with IGF blockers for the treatment of invasive breast cancer, and Insulin/IGF1R activation and IGF+ stroma cells as potential biomarker candidates for further evaluation.
\end{abstract}

Electronic supplementary material The online version of this article (https://doi.org/10.1038/s41388-017-0115-x) contains supplementary material, which is available to authorized users.

Ainhoa Mielgo

amielgo@liverpool.ac.uk

1 Department of Molecular and Clinical Cancer Medicine, University of Liverpool, Liverpool, UK

2 Department of Physiology, University of Liverpool, Liverpool, UK

3 Department of Pathology, University of California San Diego, La Jolla, USA

4 Boehringer Ingelheim RCV GmbH \& Co KG, Pharmacology and Translational Research, Vienna, Austria

5 Boehringer Ingelheim RCV GmbH \& Co KG Medicine and Translational Research, Vienna, Austria

6 Department of Urology, University Hospital Grosshadern, Ludwig-Maximilians-University, Munich, Germany

\section{Introduction}

Breast cancer is the leading cause of cancer death in females worldwide, and is characterized by a high proliferation rate, an increased capacity to metastasize, and its ability to resist standard therapies [1]. Triple-negative breast cancer (TNBC) is a highly metastatic subtype of breast cancer that accounts for $\sim 20 \%$ of all breast cancer cases and has limited efficacious treatment options [2]. Current standard treatments for metastatic disease include radiotherapy and chemotherapy [3, 4]. TNBC has a poorer survival rate, its biology is comparatively less well-understood and currently no effective specific targeted therapy is readily available [5]. Breast cancer has a propensity to give rise to distant metastasis at sites such as the lungs, bone, and brain, which can present up to 10 years after treatment [6]. Patients with metastatic breast cancer ultimately often become resistant to current chemotherapy treatments and as a result account for $>90 \%$ of breast cancer deaths [7], highlighting the need for new therapeutic targets to treat metastatic burden more effectively.

Tumor progression and response to therapy is not only dependent on tumor intrinsic mechanisms but also involves 

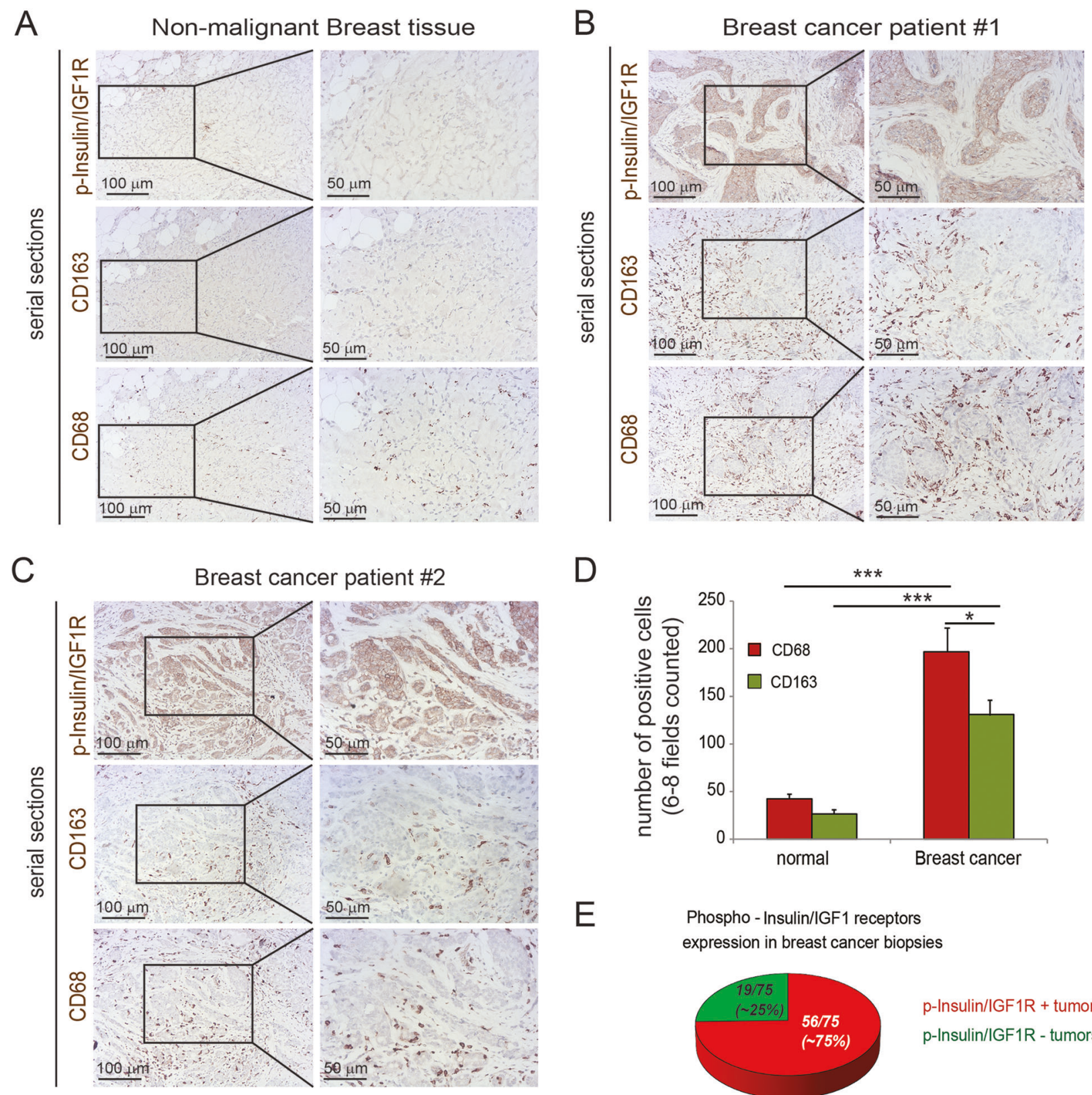

D

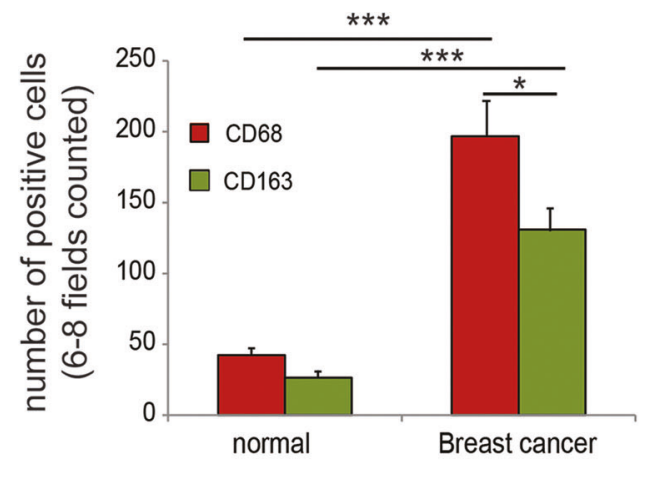

E

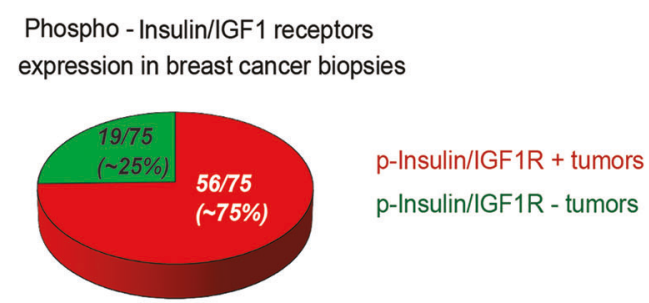

F

Positive correlation between p-Insulin/IGF1R expression
and number of CD163+ intra-tumoral macrophages
\begin{tabular}{|c|c|c|c|}
\hline & $\begin{array}{c}\text { p-Insulin/IGF1R } \\
\text { - tumors }\end{array}$ & $\begin{array}{c}\text { p-Insulin/IGF1R } \\
\text { tumors }\end{array}$ & Total \\
\hline $\begin{array}{c}\text { CD163+ } \\
\text { None/Low }\end{array}$ & 12 & 20 & 32 \\
\hline $\begin{array}{c}\text { CD163+ } \\
\text { Moderate/ High }\end{array}$ & 7 & 36 & 43 \\
\hline Total & 19 & 56 & 75 \\
\hline
\end{tabular}

Chi-square: $4.37 ; p=0.04$

G

Positive correlation between $\mathrm{p}$-Insulin/IGF1R expression and tumor stage

\begin{tabular}{|c|c|c|c|}
\hline & $\begin{array}{c}\text { p-Insulin/IGF1R } \\
\text { \& CD163+ tumors }\end{array}$ & $\begin{array}{c}\text { Other } \\
\text { tumors }\end{array}$ & Total \\
\hline $\begin{array}{c}\text { Tumour stage } \\
\mathbf{1}\end{array}$ & 5 & 14 & 19 \\
\hline $\begin{array}{c}\text { Tumour stage } \\
\text { 2A, 2B, 3A, 3B }\end{array}$ & 27 & 21 & 48 \\
\hline Total & 32 & 35 & 67 \\
\hline
\end{tabular}

Chi-square: $4.89 ; p=0.03$

modulation by surrounding non-malignant stromal cells in the tumor microenvironment $[8,9]$. Macrophages are the most abundant leukocytes in the breast tumor

microenvironment [10] and an increase in tumor-associated macrophages (TAMs) correlates with a poorer prognosis in patients [11-13]. Macrophages can be polarized into M1- 
Fig. $175 \%$ of breast cancer patients have activated Insulin/IGF1 receptors and Insulin/IGF-1 receptor activation positively correlates with macrophage infiltration and advanced tumor stage. a Serial sections of biopsies from non-malignant breast tissue immunohistochemically stained for phospho-Insulin/IGF1 receptor, CD163 and CD68. Scale bars, $100 \mu \mathrm{m}$ and $50 \mu \mathrm{m}$. b and c Serial sections of biopsies from breast cancer patients immunohistochemically stained for phospho-insulin/IGF1 receptor, CD163, and CD68. Scale bars, $100 \mu \mathrm{m}$ and $50 \mu \mathrm{m}$. d Bar graph depicting the quantification of CD68 and CD163 positive macrophages in non-malignant breast tissue and breast cancer tissue samples. Error bars represent s.d. $(n=3)$; * twotailed $p$-value $\leq 0.05$, *** two-tailed $p$-value $\leq 0.005$ using a student's $t$-test. e Pie diagram representing the percentage of phospho-Insulin/ IGF-1 receptor positive (red) and negative (green) tumors assessed in a tissue microarray containing biopsies from 75 breast cancer patients. $f$ Contingency table and results from statistical analysis showing a positive correlation between phospho-Insulin/IGF-1 receptor expression in breast tumors and increased CD163+ macrophage infiltration. Chi-square $=4.37 ; p=0.04$. g Contingency table and results from statistical analysis showing a positive correlation between phosphoInsulin/IGF1 receptor and CD163 + macrophages co-expression and tumor stage. Chi-square $=4.89 ; p=0.03$

like anti-tumorigenic macrophages and M2-like protumorigenic macrophages [14-16]. M2-like macrophages can influence tumor initiation, progression, metastasis [1719], and resistance to therapies [20-22].

Cancer progression relies on the continued propagation of cancer cells, which can be stimulated by external ligands activating signaling pathways of tumor cell survival and proliferation, even when challenged with chemotherapy [23-26]. The insulin-like growth factor (IGF) signaling axis has been implicated in promoting cancer progression in several tumor types including breast cancer [27-29], and in breast cancer resistance to estrogen and HER2 receptor inhibition [27, 30-32]. Interestingly, Fagan et al. [33] showed that tamoxifen-resistant $\mathrm{ER}+$ cells showed a reduction in the number of IGF-1 receptors, whereas the number of insulin receptors and AKT phosphorylation levels remained unaltered when stimulated with Insulin and IGF-2, suggesting that both IGF-1 and IGF-2 signaling may support resistance of breast cancer cells to therapies. However, the role of IGF signaling in tumor progression and resistance to chemotherapy in breast cancer is not completely understood yet [32]. We and others have recently shown that stroma-derived IGFs promote survival of cancer cells leading to therapy resistance in pancreatic and brain cancer models, respectively [22, 34]. In the current studies, we aimed to investigate the role of stromaderived IGF in breast cancer progression and metastasis, and to explore the therapeutic opportunity of blocking IGF signaling in combination with chemotherapy for the treatment of breast cancer.

\section{Results}

\section{Insulin and IGF-1 receptors are activated on tumor cells in biopsies from breast cancer patients, and this positively correlates with increased TAM infiltration and advanced tumor stage}

Macrophages have an important role in breast cancer progression and metastasis $[35,36]$ and have been shown to express high levels of IGFs in other cancer types [22, 34], but the role of IGF-expressing macrophages in breast cancer has not yet been explored. To investigate whether IGFsignaling pathways are activated in invasive breast cancer progression and whether their activation correlates with macrophage infiltration, we first evaluated the activation status of insulin and IGF-1 receptors in biopsies from breast cancer patients, and the levels of infiltrated TAMs. Immunohistochemical staining of serial sections of non-malignant breast tissue (Fig. 1a) and breast cancer patients' tissues (Fig. 1b, c) revealed an increase in phospho-insulin/IGF-1 receptor levels in the breast cancer tissues along with increased infiltration of CD68+ (pan-myeloid/macrophage marker) and CD163+ (marker commonly used to identify pro-tumorigenic M2-like macrophages) macrophages (Fig. 1a-d). Analysis of a tissue microarray (TMA) containing samples from 75 breast cancer patients, with different tumor stages but unspecified subtype, showed that Insulin/IGF-1R signaling was activated in 56 of $75(\sim 75 \%)$ patients (Fig. 1e and Supplementary Table. S1). Activation of insulin/IGF-1 receptors positively correlates with increased infiltration of CD163+ macrophages in the tumor (Fig. 1f) and with advanced tumor stage (Fig.1g).

\section{$87 \%$ of patients with invasive breast cancer have insulin/IGF-1 receptors activated}

As insulin/IGF-1 receptors activation positively correlates with advanced tumor stage, we further analyzed biopsies from patients with invasive breast cancer. Immunohistochemical staining revealed that invasive breast cancer also shows increased phospho-insulin/IGF-1 receptor levels in tumor cells surrounded by CD163 + macrophages (Fig. 2a). Analysis of a TMA containing 90 samples from patients with invasive breast cancer showed that 78 of $90(\sim 87 \%)$ of these patients have Insulin/IGF1 receptors activated (Fig. 2b, upper pie diagram, and Supplementary Table S2). Among these 90 samples, 51 were TNBC of which 45 ( $88.2 \%$ ) showed activation of Insulin/IGF1 receptors (Fig. 2b, lower, left pie diagram), 13 were hormone-receptor positive $(\mathrm{HR}+)$ of which $12(\sim 92 \%)$ showed activation of Insulin/IGF1 receptors (Fig. 2b, lower, middle pie diagram), and 19 were HER2 positive (HER2+) of which $16(\sim 84 \%)$ 
A
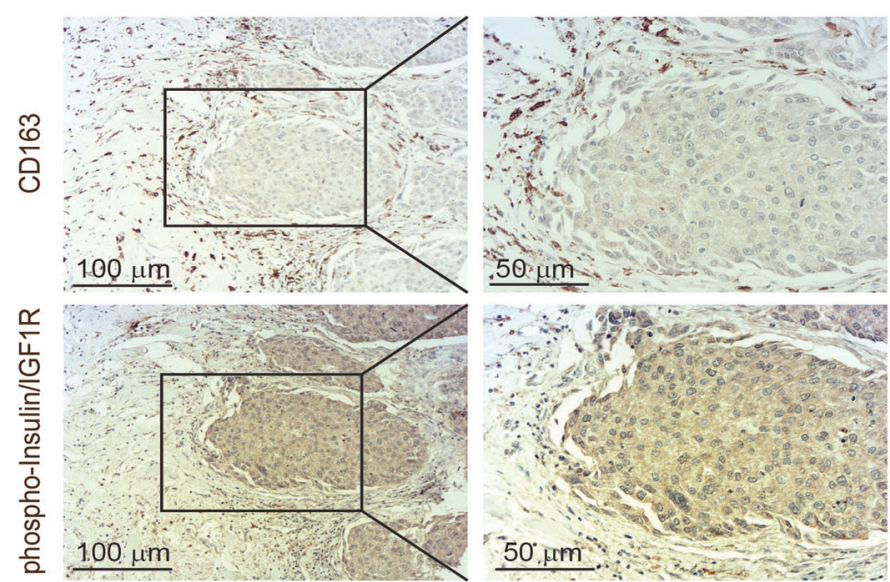

B

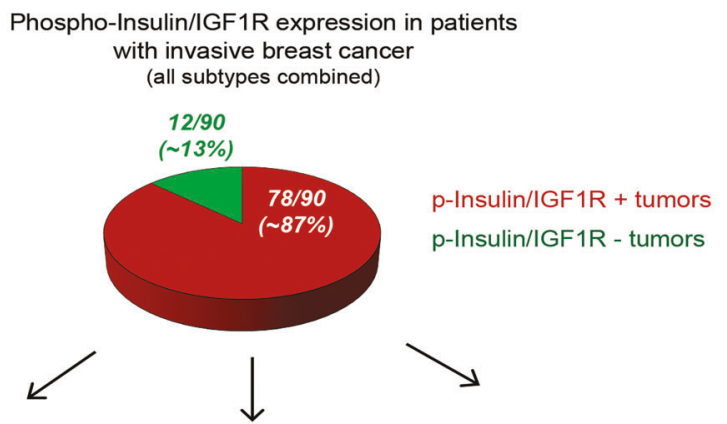

Phospho-Insulin/IGF1R expression in TNBC patients

$6 / 51$

$(\sim 11.8 \%)$

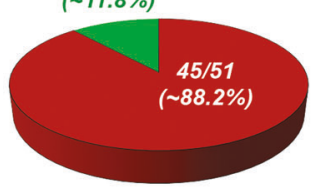

Phospho-Insulin/IGF1R expression in $\mathrm{HR}+$ patients

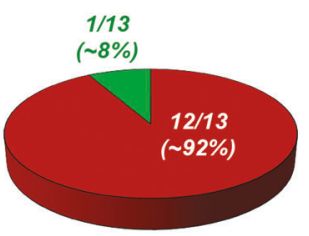

Phospho-Insulin/IGF1R expression in HER2+ patients

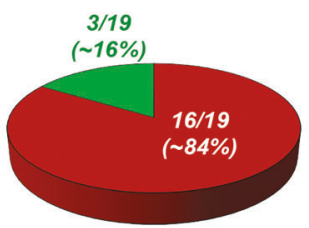

C

IGF1
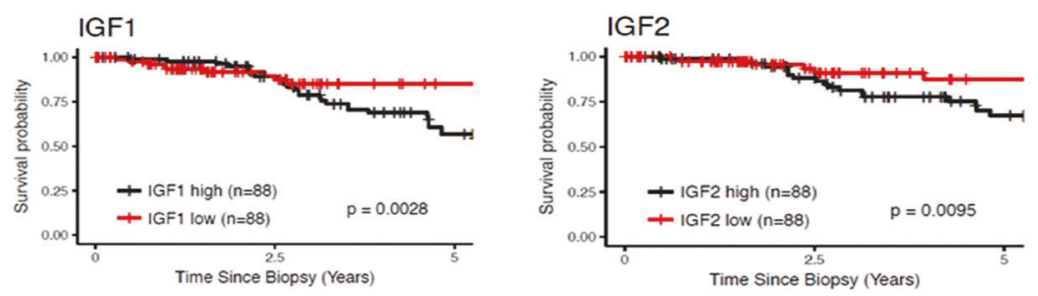

CD163
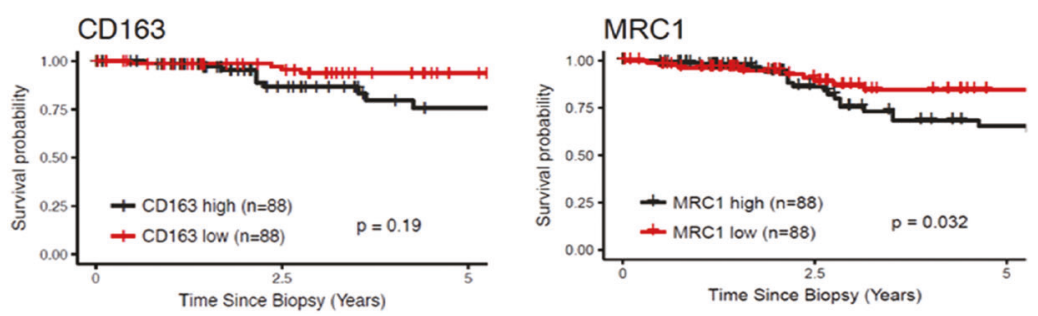

Fig. 2 Eighty-seven percent of patients with invasive breast cancer have activated Insulin/IGF1 receptors. a Immunohistochemical staining of invasive breast cancer tissue serial sections stained for phosphoInsulin/IGF1 receptor and CD163. Scale bars, $100 \mu \mathrm{m}$ and $50 \mu \mathrm{m}$. b Upper diagram: Pie diagram representing the percentage of phosphoInsulin/IGF1 receptor positive (red) and negative (green) tumors

assessed in tissue microarray (TMA) containing biopsies from 90 consented patients with invasive breast cancer. Lower diagrams: represent the percentage of phospho-Insulin/IGF1 receptor positive (red) and negative (green) tumors of the molecular subsets, TNBC, HR + , and HER2 +. c Expression levels of $I g f-1, I g f-2, c d 163$, and $m r c l$ associated with survival in breast cancer patients 
A

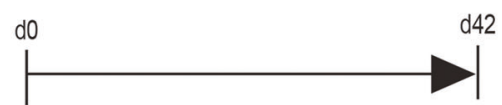

$$
\begin{aligned}
& \text { Orthotopic } \\
& \text { implantation } \\
& \text { of Py230 luciferase } \\
& \text { cells in isogenic } \\
& \text { recipient mouse }
\end{aligned}
$$

F4/80/nuclei

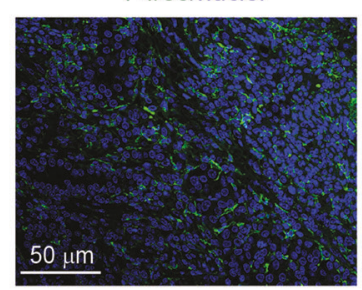

Merge

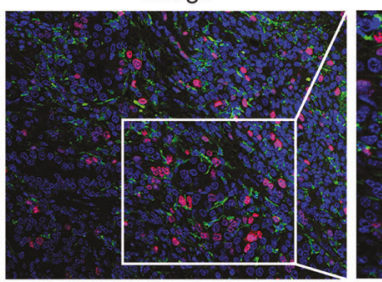

Ki67/nuclei
PrimaryTumors Harvested

- Tissue processed

- FACS cell sorting:

(TAMs, CAFs, tumor cells)

B
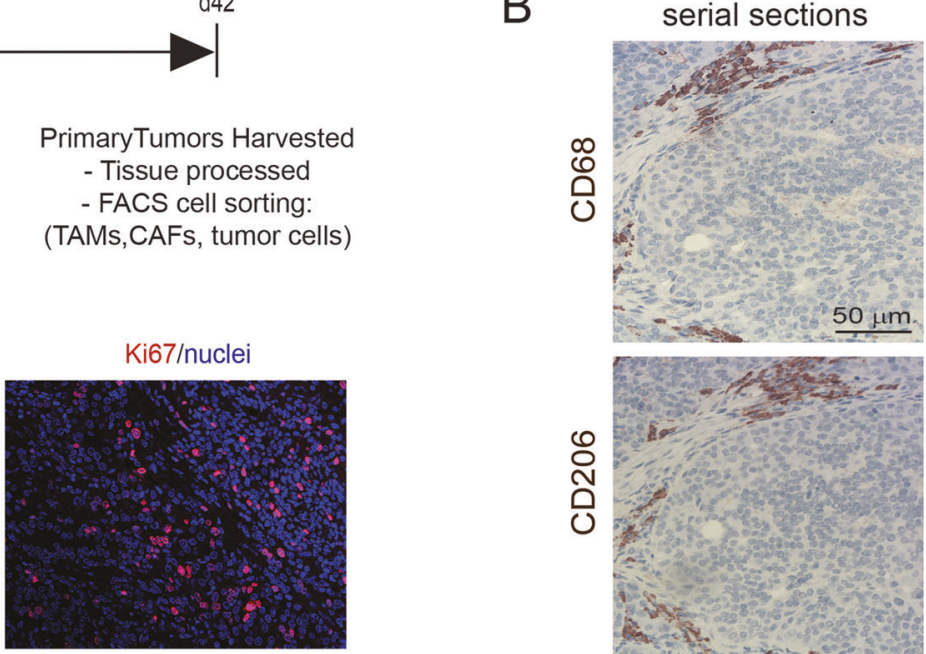

F4/80/ Ki67/ nuclei

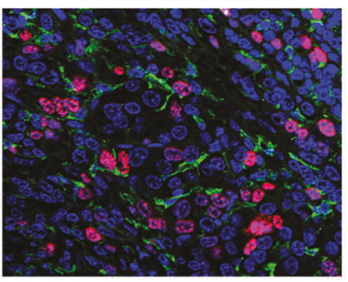

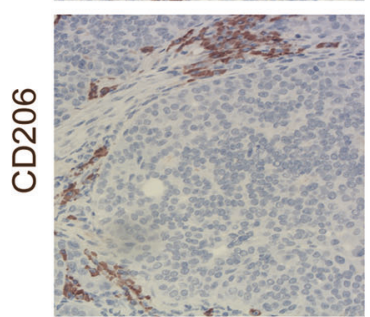

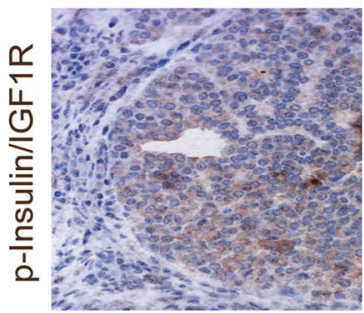

C

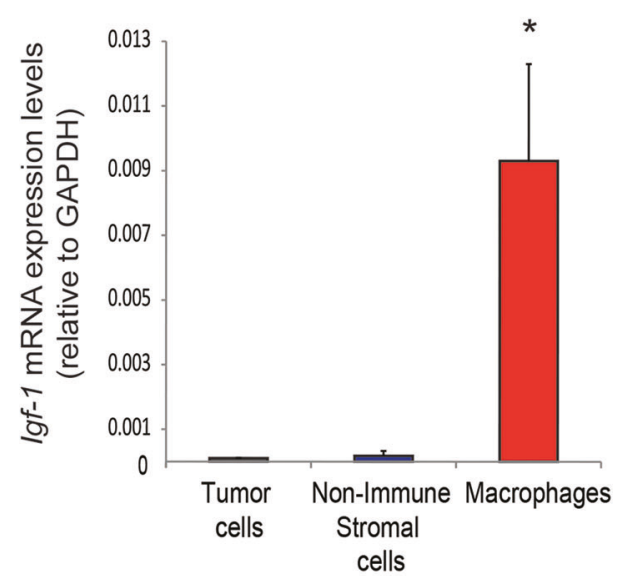

E

aSMA/nuclei

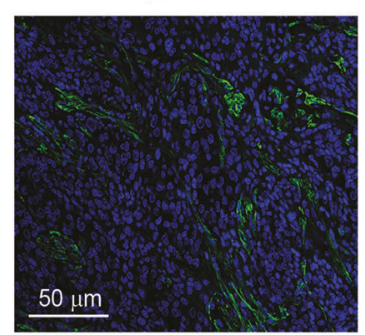

Ki67/nuclei

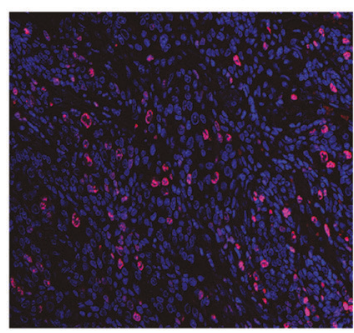

D

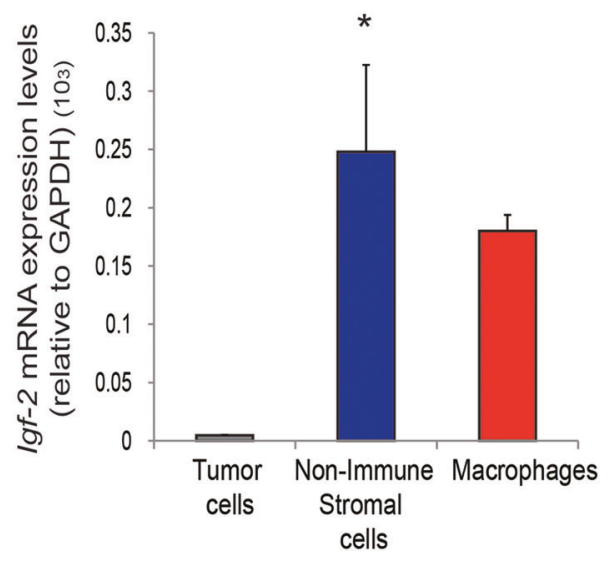

Merge

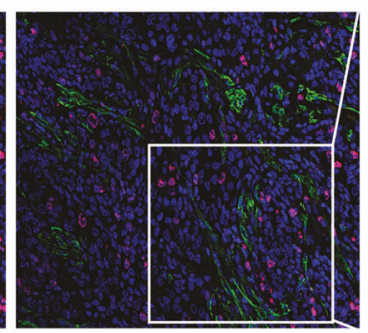

aSMA/ Ki67/nuclei

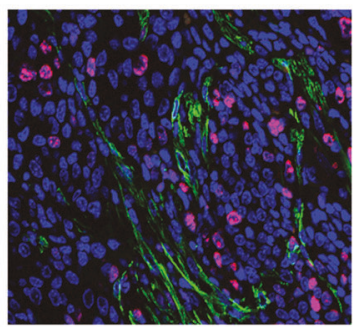


Fig. 3 TAMs and CAFs are the main sources of IGF-1 and IGF-2 in invasive breast adenocarcinomas. a PY230 tumor cells were subcutaneously implanted into the third mammary gland of syngeneic recipient mice. Images show immunofluorescent staining for F4/80 (green), Ki67 (red), and nuclei (blue) in murine breast cancer tissue harvested at day 42 after tumor implantation. Scale bar $50 \mu \mathrm{m}$. b Serial sections of immunohistochemical staining for CD68, CD206 and phospho-Insulin/IGF1 receptor in murine breast tumors. Scale bar $50 \mu \mathrm{m}$. c Igf-1 mRNA expression levels were quantified in tumor cells, non-immune stromal cells and tumor-associated macrophages isolated from murine breast cancer tumors by flow cytometry. Error bars represent s.e. $(\mathrm{n}=3), * p$-value $\leq 0.05$ using one-way ANOVA and Bonferroni post hoc test. d Igf-2 mRNA expression levels were quantified in tumor cells, non-immune stromal cells and tumorassociated macrophages isolated from murine breast cancer tumors by flow cytometry. Error bars represent s.e. $(n=3),{ }^{*} p$-value $\leq 0.05$ using one-way ANOVA and Bonferroni post hoc test. e Immunofluorescent images of $\alpha$ SMA (green), Ki67 (red), and nuclei (blue) in breast tumors. Scale bar $50 \mu \mathrm{m}$

showed activation of Insulin/IGF1 receptors (Fig. 2b, lower, right pie diagram). Using the cancer genome atlas database we also found that increased gene expression of $I g f-1, I g f-2$, and the M2-like macrophage markers $c d 163$ and $m r c l$ positively correlates with reduced survival in breast cancer patients (Fig. 2c). Together these results suggest an important role for IGF signaling in invasive breast cancer of all subtypes, including TNBC.

\section{TAMs and fibroblasts are the main sources of IGF-1 and IGF-2 in invasive breast cancer}

To further understand the correlation between activation of Insulin/IGF1 receptors and increased TAMs infiltration, we used an orthotopic syngeneic TNBC pre-clinical model, which has been shown to recapitulate the human disease progression [37]. In brief, we isolated murine breast cancer cells (Py230) from the genetically engineered spontaneous breast cancer model MMTV-PyMT and transduced isolated cells with a reporter lentivirus expressing zsGreen/luciferase allowing in vivo imaging of tumor burden. To induce breast tumor burden, Py230zsGreen/luciferase cells were orthotopically implanted into the mammary fatpad of isogenic immunocompetent recipient mice. Forty-two days after implantation, primary tumors were surgically removed and tumor tissue sections were analyzed by immunofluorescent and immunohistochemical staining. We found that tumors were highly infiltrated by macrophages (F4/80+, CD68+, $\mathrm{CD} 206+)$ that surround proliferating tumor cells (Ki67+) (Fig. 3a), which also express phosphorylated/activated insulin/IGF-1 receptors (Fig. 3b). Thus, similar to what we observed in human biopsies, murine breast cancer cells, which are spatially located in close proximity to M2-like TAMs, have activated Insulin/IGF-1 receptors.
Next, we aimed to identify the source of insulin and IGF1 receptors ligands, namely IGF- 1 and IGF-2, in the tumor microenvironment. Therefore, we enzymatically digested primary tumors to prepare single cells suspensions and isolated tumor cells, non-immune stromal cells and macrophages, by flow cytometry cell sorting (Supplementary Fig. S1A B). Gene expression analysis of isolated cell populations revealed that TAMs are the main source of $I g f$ 1 and that both TAMs and cancer-associated fibroblasts (CAFs) are major sources of Igf-2 in the breast tumor microenvironment (Fig. 3c, d). Immunofluorescent staining of $\alpha$ SMA and Ki67 in the murine breast tumors showed that $\alpha \mathrm{SMA}+$ stromal cells, which appear to be a major source of IGF-2, also surround actively dividing tumor cells (Fig. 3e). IGF-1 and IGF-2 are also expressed in the stroma surrounding cancer cells in human TNBC samples (Supplementary Fig. S2A), and gene expression analysis of Igf- 1 and $I g f-2$ in human MDA-MB-231 TNBC cells and primary human macrophages revealed that human macrophages express high levels of $I g f-1$ and $I g f-2$, whereas there was very little expression of these ligands in the breast cancer cells (Supplementary Fig. S2B and C).

\section{Metastasis-associated macrophages and fibroblasts remain the main sources of IGF-1 and IGF-2 in pulmonary metastatic lesions}

Breast cancer is a highly invasive disease and often metastasizes to the lung. Orthotopically implanted Py230 breast cancer cells into syngeneic recipient mice effectively metastasized to the lung, where they formed metastatic tumors (Fig. 4a). We wondered whether IGF-1 and IGF-2 might also be expressed in the metastatic tumor microenvironment and thereby provide a survival/proliferative signal to disseminated cancer cells. To address this question, we analyzed metastatic lung tumors from our animal model for the expression of $I g f-1$ and $I g f-2$ in the metastasisassociated stromal cells.

Metastatic tumors in lungs were first confirmed by bioluminescence ex vivo imaging and by hematoxylin and eosin (H\&E) staining (Fig. 4a). Immunofluorescent staining showed that pulmonary metastatic lesions are surrounded by macrophages $(\mathrm{F} 4 / 80+)$ and myofibroblasts $(\alpha \mathrm{SMA}+)$ (Fig. 4b). Similar to what we observe at the primary site, metastasis-associated macrophages and fibroblasts express high levels of $I g f-1$ and $I g f-2$, whereas disseminated breast cancer cells do not express these ligands (Fig. 4c, d). Together, these findings provide evidence that macrophages and fibroblasts are the main sources of IGF-1 and IGF-2 both at the primary and the metastatic site in invasive breast cancer. 
A

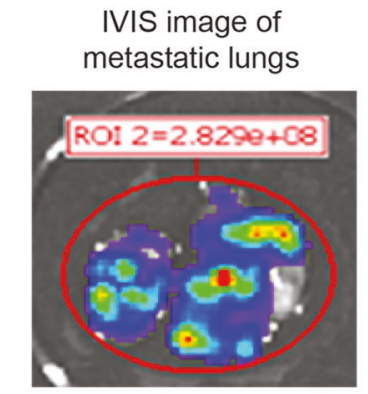

IVIS image of
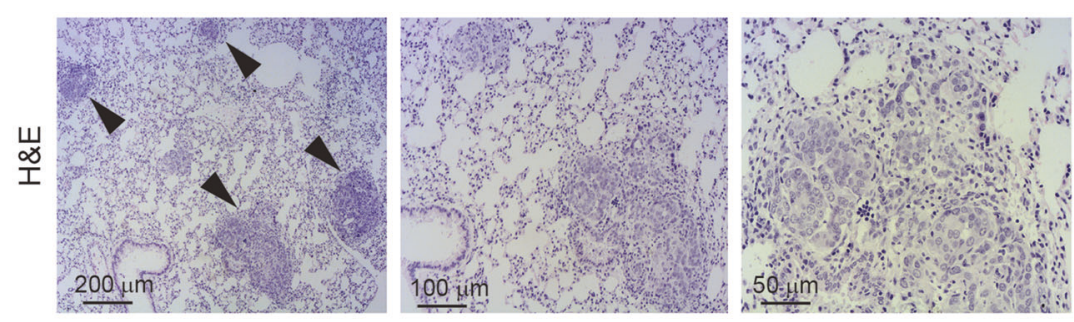

B

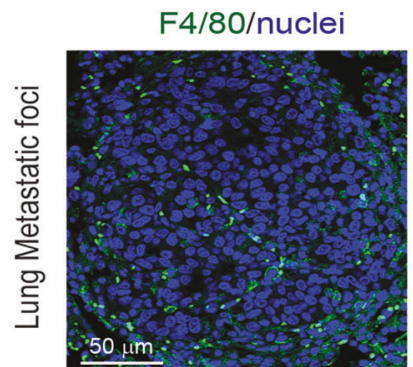

$\alpha$ SMAnuclei
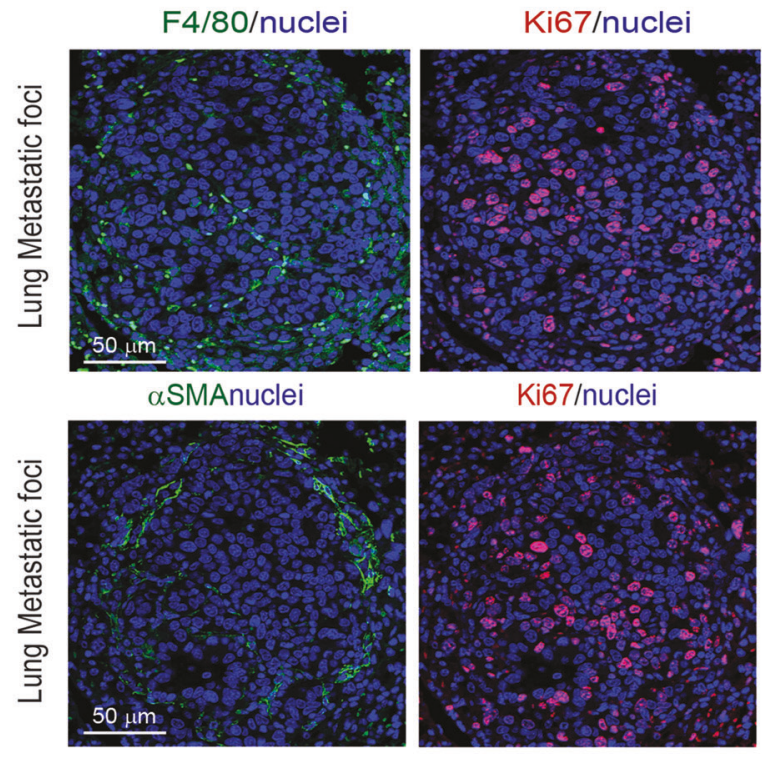

Ki67/nuclei
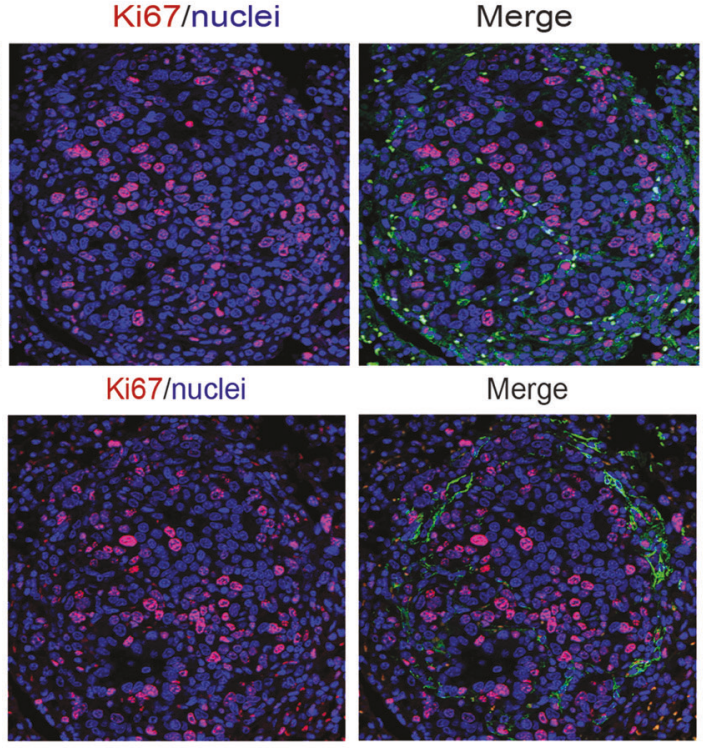

Merge

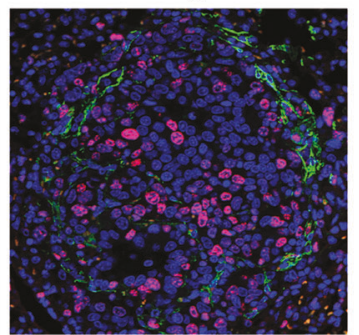

\section{C}

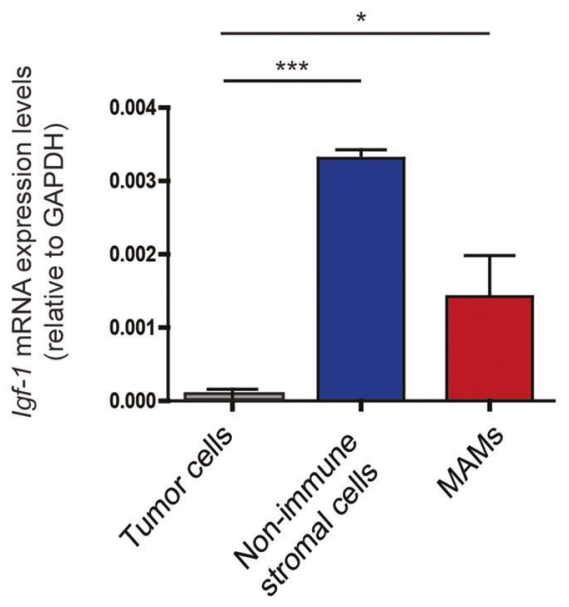

Fig. 4 Metastasis-associated macrophages and fibroblasts express IGF1 and IGF-2 in metastatic lungs. a Left, identification of metastatic tumor lesions in the lung by bioluminescent imaging technique of orthotopically implanted PY230 $30^{\text {luc }}$ breast cancer cells. Right, images show $\mathrm{H} \& \mathrm{E}$ staining of metastatic foci in the lungs. Arrows indicate metastatic foci, scale bars $200 \mu \mathrm{m}, 100 \mu \mathrm{m}$, and $50 \mu \mathrm{m}$. b Immunofluorescent images of lung metastatic foci stained for F4/80 (green), $\alpha$ SMA (green), Ki67 (red), and nuclei (blue). Scale bar $50 \mu \mathrm{m}$. c Quantification of Igf-1 mRNA expression levels in metastatic tumor cells, metastasis-associated non-immune stromal cells and metastasis-

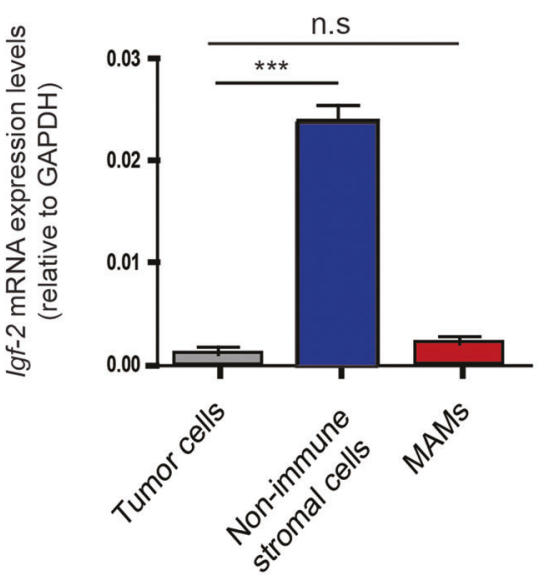

associated macrophages isolated from pulmonary metastasis. Error bars represent s.e. $(n=3)$, * $p$-value $\leq 0.05$, *** $p$-value $\leq 0.0001$ using one-way ANOVA and Bonferroni post hoc test. d) Quantification of Igf-2 mRNA expression levels in metastatic tumor cells, metastasis-associated non-immune stromal cells and metastasisassociated macrophages isolated from pulmonary metastasis. Error bars represent s.e. $(n=3), * * * p$-value $\leq 0.05$ using one-way ANOVA and Bonferroni post hoc test 
A

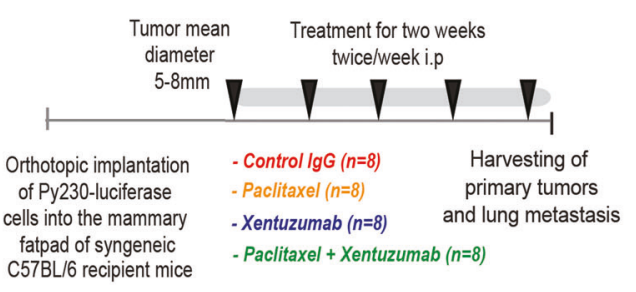

B

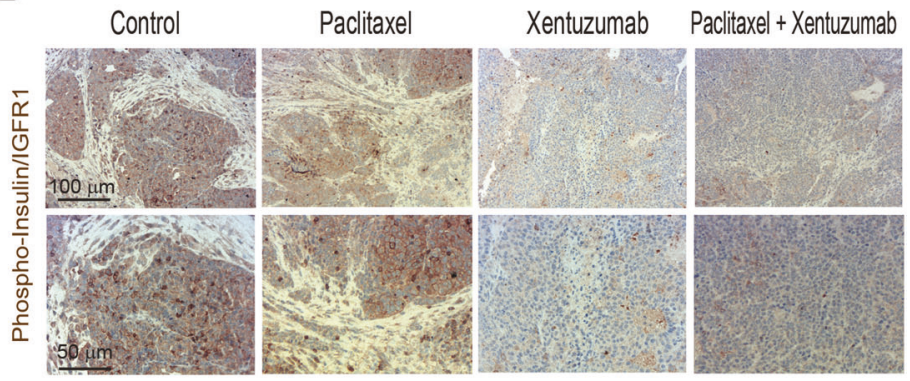

C

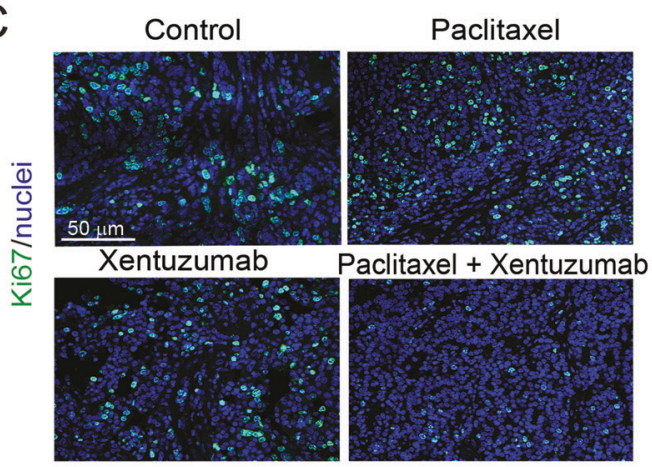

D

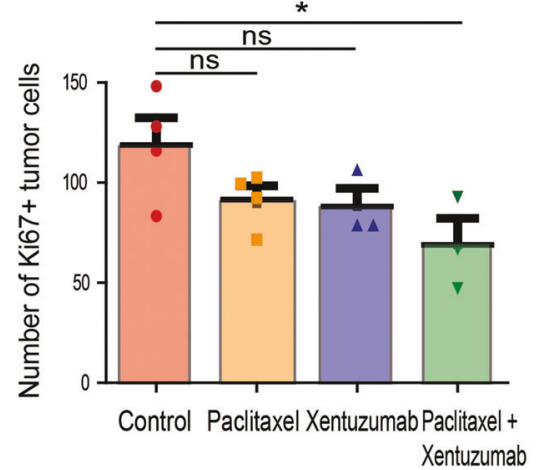

E

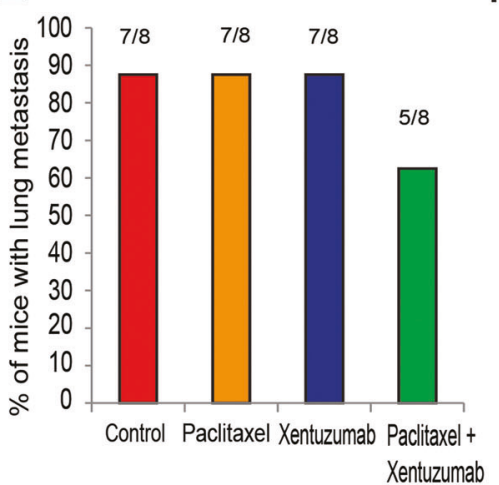

$\mathrm{H}$

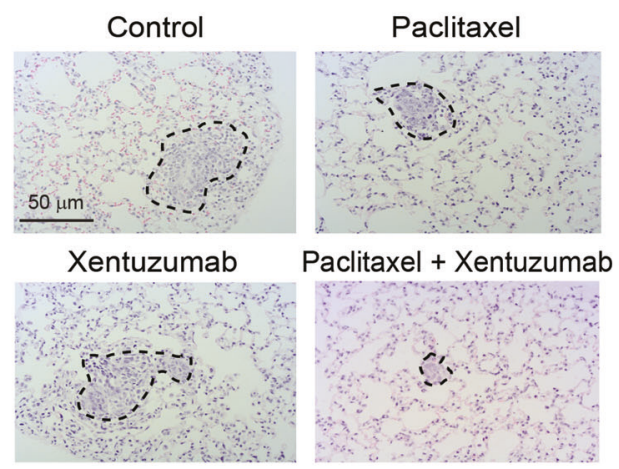

F

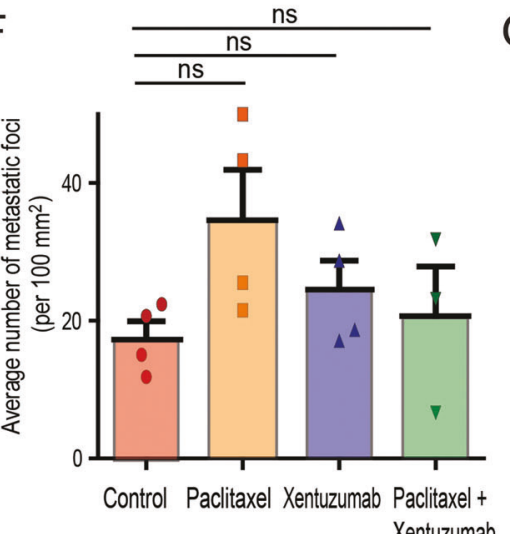

Xentuzumab

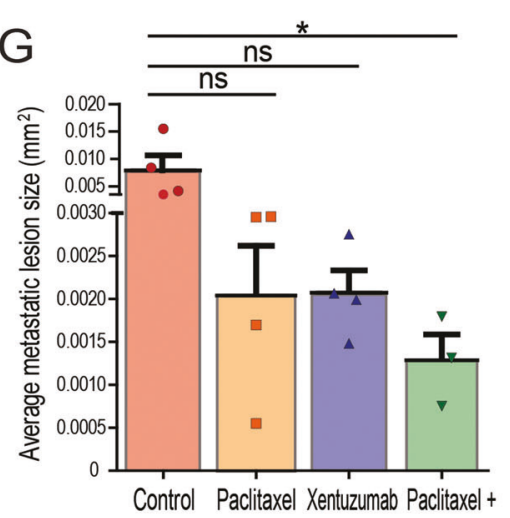

Xentuzumab

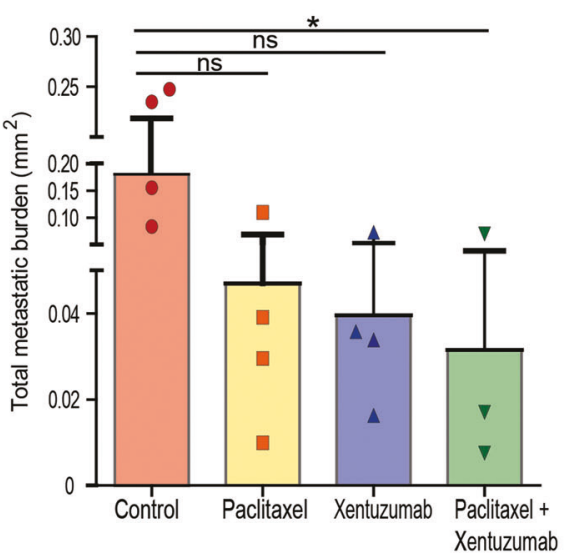


Fig. 5 Combined treatment of IGF blocking antibody with paclitaxel decreases breast cancer proliferation and metastasis in Py 230 model. a Py230 luciferase cells were orthotopically implanted into the third mammary fatpad of syngeneic C57BL/6 recipient mice and mice were treated, starting when tumors reached between $5-8 \mathrm{~mm}^{2}$, twice a week i.p., with control IgG antibody, IGF blocking antibody xentuzumab $(100 \mathrm{mg} / \mathrm{kg})$, paclitaxel $(100 \mathrm{mg} / \mathrm{kg})$, or a combination of xentuzumab with paclitaxel ( $n=8$ mice per group). b Immunohistochemical staining of phospho-insulin/IGF-1R in breast tumors treated with IgG (control), paclitaxel, xentuzumab or paclitaxel + xentuzumab. Scale bars $100 \mu \mathrm{m}$ and $50 \mu \mathrm{m}$. c Immunofluorescent staining of Ki67 in primary tumors treated with IgG (control), paclitaxel, xentuzumab, or paclitaxel + xentuzumab. Scale bar $50 \mu \mathrm{m}$. d Quantification of Ki67positive tumor cells in tumors treated with $\operatorname{IgG}$ (control), paclitaxel, xentuzumab or paclitaxel + xentuzumab. 3-5 fields counted/mouse tumor, $n=3-4$ mice per treatment group, $* p \leq 0.05$ using one-way ANOVA and Bonferroni post hoc test. e Percentage of mice presenting with lung metastasis per treatment group. ( $n=8$ mice/group). f Quantification of number of lung metastatic foci per $100 \mathrm{~mm}^{2}$ in mice treated with control IgG, paclitaxel, xentuzumab, or paclitaxel + xentuzumab. ns, non-significant differences using one-way ANOVA and Bonferroni post hoc test. $\mathbf{g}$ Average size of pulmonary metastatic lesions $\left(\mathrm{mm}^{2}\right)$ in mice treated with control $\mathrm{IgG}$, paclitaxel, xentuzumab, or paclitaxel + xentuzumab, $* p \leq 0.05$, using one-way ANOVA and Bonferroni post hoc test. $\mathbf{h} \mathrm{H} \& \mathrm{E}$ staining of lung metastatic foci in mice treated with control IgG, paclitaxel, xentuzumab, or paclitaxel + xentuzumab. Scale bar $50 \mu \mathrm{m}$. i Total metastatic burden $\left(\mathrm{mm}^{2}\right)$ in mice treated with control IgG, paclitaxel, xentuzumab, and paclitaxel with xentuzumab, $* p \leq 0.05$, using one-way ANOVA and Bonferroni post hoc test

\section{Combination treatment of invasive breast cancer with paclitaxel and IGF blocking antibody reduces}

\section{tumor cell proliferation and metastasis in a syngeneic orthotopic Py230 model}

To determine whether IGF signaling affects breast cancer progression, metastasis and response to paclitaxel, a standard chemotherapeutic agent used to treat breast cancer, we treated mice orthotopically implanted with Py230 TNBC cells, with control IgG antibody, IGF-1/2 blocking antibody xentuzumab, paclitaxel, or xentuzumab with paclitaxel (Fig. 5a). As expected, control and paclitaxel treated mice showed high levels of insulin and IGF-1 receptor activation in the primary breast cancer tumors, whereas the xentuzumab and xentuzumab with paclitaxel treated groups showed markedly reduced levels of insulin and IGF-1 receptor activation, confirming that xentuzumab has reached the tumor and has blocked IGF signaling (Fig. 5b) [38]. No differences were seen in primary tumor growth (Supplementary Fig. S3A), in tumor cell death (Supplementary Fig. S3B) or in TAM infiltration of primary tumors (Supplementary Fig. S3C) between the different treatment groups. However, control IgG-treated mice showed higher levels of Ki67+ proliferating tumor cells, which were modestly reduced by both paclitaxel and xentuzumab single treatments and significantly reduced by the combination treatment of xentuzumab with paclitaxel (Fig. 5c, d). In addition, mice treated with the combination of xentuzumab with paclitaxel treatment showed a reduction in lung metastasis incidence (Fig. 5e). Although there were no significant differences in the number of metastatic foci in the different treatment groups (Fig. 5f), we found a significant reduction in the size of metastatic lesions and overall lung metastatic burden in the group treated with both paclitaxel and xentuzumab (Fig. 5g-i). These data suggest that initial metastatic seeding is not affected by the combination treatment, but that paclitaxel/xentuzumab treatment impairs metastatic outgrowth of disseminated breast cancer cells.

\section{Combination treatment of invasive breast cancer with paclitaxel and IGF blocking antibody reduces tumor cell proliferation and metastasis in a syngeneic orthotopic 4T1 model}

To confirm the results from the Py230 experiment in another model, 4T1-zsGreen/luciferase cells were implanted into the mammary fatpad of syngeneic Balb/c mice and treated with isotype control antibody, paclitaxel, xentuzumab, or paclitaxel with xentuzumab (Fig. 6a). In accordance with our previous findings, insulin and IGF-1R receptor activation was markedly reduced in the mice treated with xentuzumab alone and paclitaxel with xentuzumab (Supplementary Fig. S4A) [38]. In this model, we found that primary tumor growth was significantly reduced by paclitaxel treatment and even further reduced by the combination treatment paclitaxel + xentuzumab (Fig. 6b). Analysis of Ki67 + proliferating cells in the primary tumor showed a significant reduction in paclitaxel treated mice and reduced further in paclitaxel with xentuzumab treated mice compared with control IgG mice (Fig. 6c, d). The numbers of lung metastatic foci were significantly reduced by both paclitaxel alone and the combination of paclitaxel + xentuzumab compared with control treatment group (Fig. 6e). However, only the combination treatment of paclitaxel + xentuzumab significantly reduced the average metastatic lesion size and the overall metastatic burden (Fig. 6f-h).

Taken together, our findings indicate that IGF-1 and 2 are highly expressed by both macrophages and fibroblasts in invasive breast cancer, and that blockade of IGF potentiates the efficacy of paclitaxel (Fig. 6i).

\section{Discussion}

Here we show that IGF-1 and 2 are secreted by macrophages and fibroblasts, both at the primary site and metastatic site in invasive breast cancer, and that blocking IGF increases the efficacy of paclitaxel, a chemotherapeutic 


\section{A}

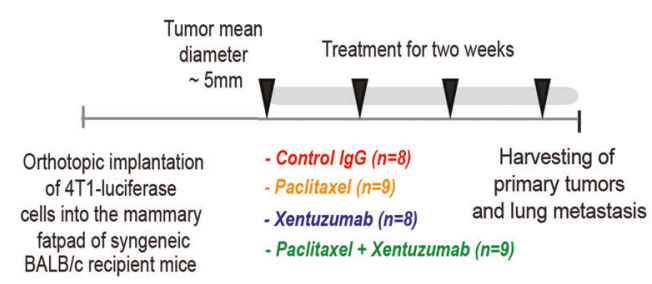

C
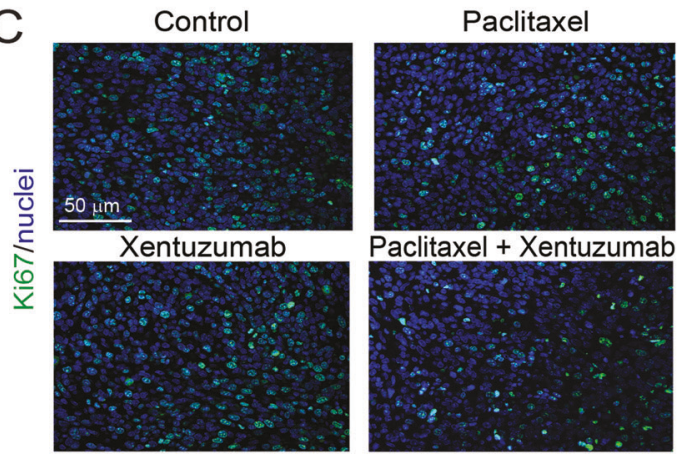

B

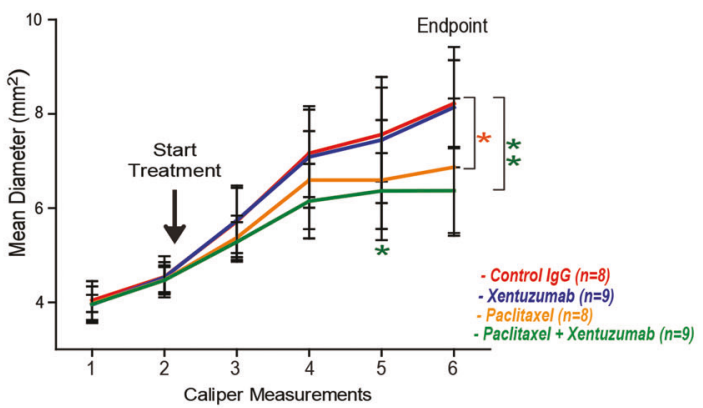

D

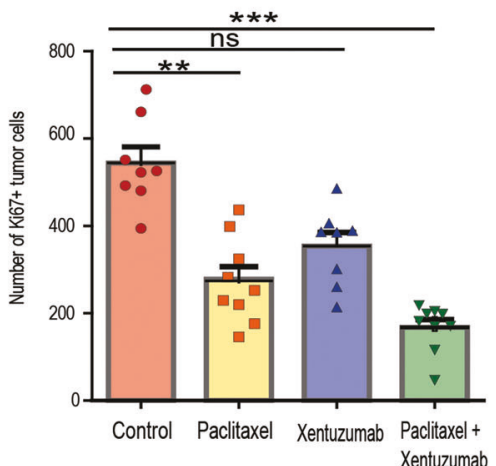

$E$

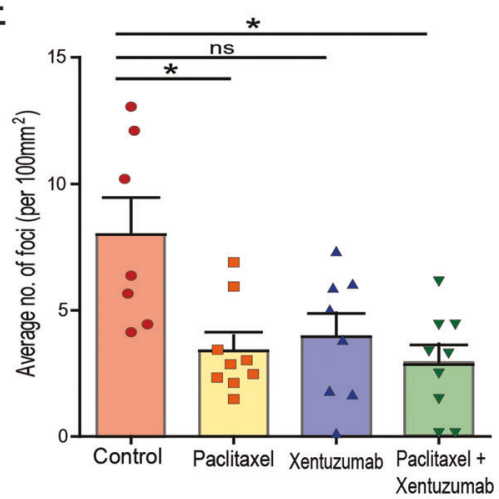

$\mathrm{F}$

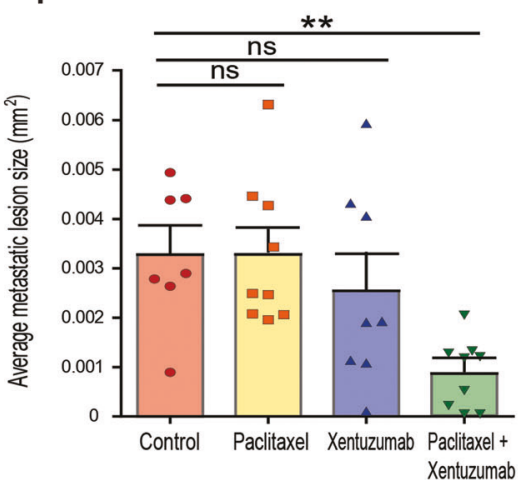

G

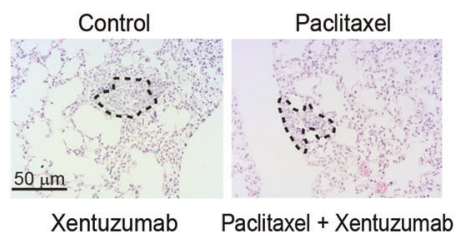

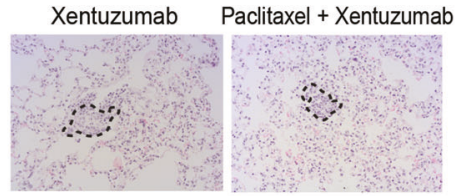

$\mathrm{H}$
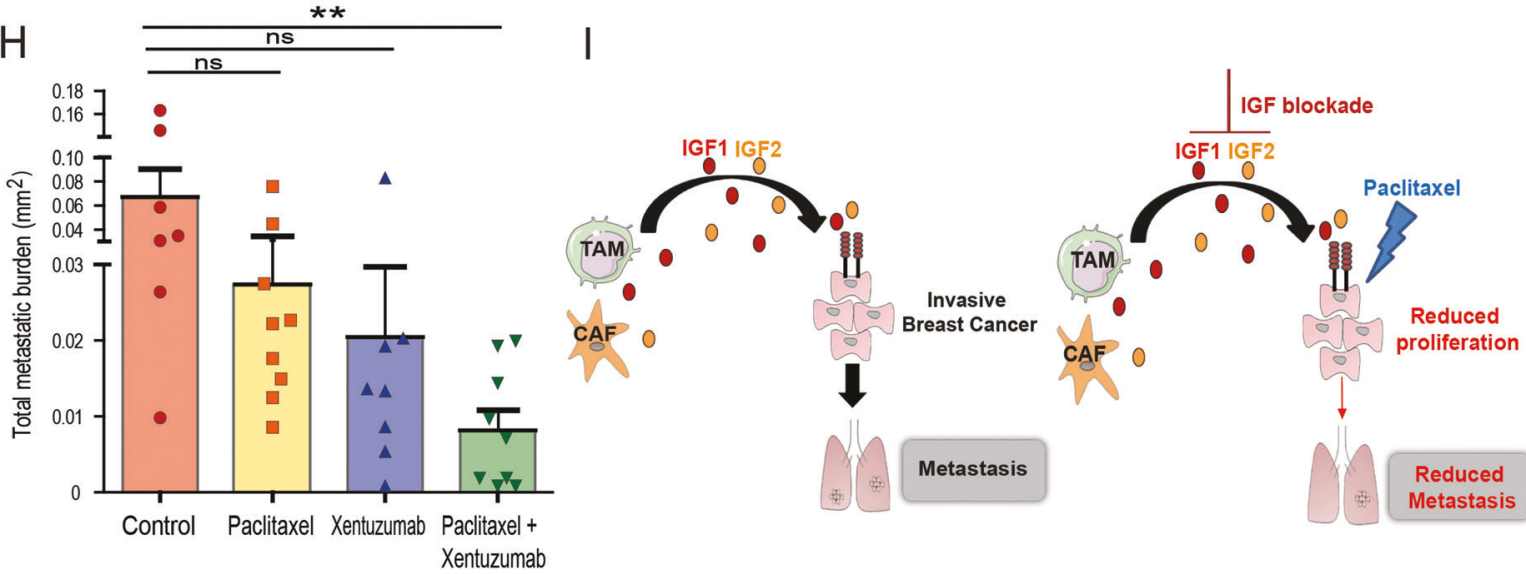

Metastasis

agent commonly used for the treatment of invasive breast cancer (Fig. 6i). Breast cancer, and in particular TNBC, remains a highly metastatic and potentially lethal disease with a need to identify additional specific molecular targets and to develop more effective therapies [4, 5]. Although IGF signaling has been shown to support progression of HR + and HER2 + breast cancer and the development of resistance to established therapies, its precise role in TNBC 
Fig. 6 Combined IGF blocking antibody with paclitaxel decreases metastatic burden in 4T1 breast cancer model. a 4T1-zsgreen/luciferase cells were orthotopically implanted into the third mammary fatpad of syngeneic Balb/c recipient mice and were treated when tumors reached $\sim 5 \mathrm{~mm}$ mean diameter, over 2 weeks the mice received four treatments by i.p. with control human IgG antibody ( $n=8$ mice), IGF blocking antibody xentuzumab $(100 \mathrm{mg} / \mathrm{kg})(n=8$ mice $)$, paclitaxel $(100 \mathrm{mg} / \mathrm{kg}) \quad(n=9$ mice $)$ or a combination of xentuzumab with paclitaxel $\left(n=9\right.$ mice). b Graph showing tumor mean diameter $\left(\mathrm{mm}^{2}\right)$ measured by calipers before and during treatment with isotype control, xentuzumab, paclitaxel, and paclitaxel with xentuzumab. Error bars represent s.e. (IgG antibody and xentuzumab $n=8$, paclitaxel and paclitaxel with xentuzumab $n=9$ ), $* p$-value $\leq 0.05, * * p$-value $\leq 0.01$ using two-way ANOVA and Bonferroni post hoc test. c Immunofluorescent staining of Ki67 in primary tumors treated with IgG (control), paclitaxel, xentuzumab, or paclitaxel + xentuzumab. Scale bar $50 \mu \mathrm{m}$. d Quantification of Ki67-positive tumor cells in tumors treated with human IgG (control), paclitaxel, xentuzumab, or paclitaxel + xentuzumab. A total of 3-5 fields counted/mouse tumor, $n=8-9$ mice per treatment group, ns, non-significant differences, $* * p \leq 0.01$, $* * * \leq 0.0001 p$ using one-way ANOVA and Bonferroni post hoc test. Images quantified using NIS-Elements Advanced Research software. e Quantification of number of lung metastatic foci per $100 \mathrm{~mm}^{2}$ in mice treated with control IgG, paclitaxel, xentuzumab, or paclitaxel + xentuzumab. Error bars represent s.e. (IgG antibody $n=7$, paclitaxel $n=9$, xentuzumab $n=8$, and paclitaxel with xentuzumab $n=9$ ) ns, non-significant differences, $* p$-value $\leq 0.05$, using one-way ANOVA and Bonferroni post hoc test. $\mathbf{f}$ Average size of pulmonary metastatic lesions $\left(\mathrm{mm}^{2}\right)$ in mice treated with control $\mathrm{IgG}$, paclitaxel, xentuzumab, or paclitaxel + xentuzumab. Error bars represent s.e., ns, nonsignificant differences, $* * p \leq 0.01$, using one-way ANOVA and Bonferroni post hoc test. $\mathbf{g}$ H\&E staining of lung metastatic foci in mice treated with control IgG, paclitaxel, xentuzumab, or paclitaxel + xentuzumab. Scale bar $50 \mu \mathrm{m}$. h Total metastatic burden $\left(\mathrm{mm}^{2}\right)$ in mice treated with control IgG, paclitaxel, xentuzumab, and paclitaxel with xentuzumab. Error bars represent s.e., ns, non-significant differences, ** $p \leq 0.01$, using one-way ANOVA and Bonferroni post hoc test. i Schematics describing the role of stroma-derived IGF-1 and 2 in regulating the response of metastatic breast cancer to paclitaxel

remains elusive [32]. In our TNBC model, we found that TAMs and CAFs secrete IGF- 1 and 2 at both the primary site and the pulmonary metastatic site. Zhang et al. [39], previously reported that CAF-derived IGF-1 primes breast cancer cells for bone metastasis. These studies both suggest that stromal-derived IGF plays an important role in the metastatic process of breast cancer.

In this study, we find that the Insulin/IGF1R signaling pathway is activated in 78 of $90(\sim 87 \%)$ of patients with invasive breast cancer and in 45 of $51(\sim 88.2 \%)$ TNBC patients, suggesting IGF may be a promising therapeutic target for this highly aggressive breast cancer subtype. We also observed that activation of Insulin/IGF1 receptor signaling positively correlates with increased levels of macrophage infiltration and advanced tumor stage in patients, suggesting that Insulin/IGF1 receptor activation and/or stroma expression of IGF could be predictive biomarker candidates for further evaluation.
To investigate the therapeutic potential of blocking IGF signaling in invasive breast cancer, we tested the IGF-1/2 blocking antibody xentuzumab (Boehringer Ingelheim) in two pre-clinical mouse models of invasive TNBC breast cancer, which metastasize to the lungs. In both models, we find that combining xentuzumab with paclitaxel results in reduced incidence of metastasis, as well as a significant reduction of tumor cell proliferation and metastatic burden compared with monotherapy. In agreement with our findings, Gooch et al. [40], previously showed that IGF-1 promotes proliferation of paclitaxel treated cells in vitro. Interestingly, xentuzumab + paclitaxel combination treatment significantly decreases the size of metastatic lesions but not the number of foci suggesting that the combination treatment affects metastatic outgrowth rather than the metastatic seeding.

IGF1R inhibitors have been assessed in clinical trials for metastatic HR + as well as TNBC but have shown limited success [41-46]. Two promising IGF ligand blocking antibodies, xentuzumab and MEDI-573, are currently being evaluated in clinical trials in $\mathrm{HR}+$ metastatic breast cancer patients in combination with everolimus and exemestane (NCT02123823) and in hormone sensitive metastatic breast cancer in combination with letrozole (NCT01446159), respectively. In contrast to IGF1R antibodies, IGF blocking antibodies neutralize both ligands IGF-1 and IGF-2 and thereby inhibit proliferative signaling through both Insulin and IGF1 receptors without affecting insulin metabolic signaling $[38,47]$.

Breast cancer cells survive poorly in isolation and participate in a complex relationship with surrounding stromal and immune cells in the tumor microenvironment, which can support tumor cell survival, proliferation, and spreading to other organs $[17,20,21,36,39]$. CAFs and TAMs are the most abundant stromal cells in solid cancers, including breast cancer. However, different populations of CAFs and TAMs with both pro- and anti-tumorigenic functions coexist in tumors [48-50]. Therefore, therapies aiming to specifically inhibit the tumor supporting functions of stromal cells, without affecting their anti-tumorigenic functions, may be more effective than ablation therapies in restraining tumor progression [26, 51]. Our findings indicate that blocking IGFs in combination with paclitaxel, decreases tumor cell proliferation and breast cancer pulmonary metastasis without affecting macrophage infiltration. In conclusion, this study suggests that stroma-derived IGFs support breast cancer metastasis and modulate its response to paclitaxel, providing the rationale for further evaluation of IGF blocking antibodies in combination with paclitaxel in the treatment of invasive breast cancer. 


\section{Materials and methods}

\section{Generation of primary PyMT-derived breast cancer cells}

Py230 cells (hormone-receptor negative and HER2 low) were generated in Ellies lab (University of California San Diego, USA) and obtained from spontaneously arising tumors in MMTV-PyMT C57B1/6 female mice by serial trypsinization and limiting dilution [52]. The mouse model used for obtaining these tumors has been described in detail previously [53, 54].

\section{Generation of 4T1 derived breast cancer cells}

4T1 cells were purchased from the ATCC and were originally obtained from a spontaneously arising mammary tumor in $\mathrm{BALB} / \mathrm{cfC} 3 \mathrm{H}$ mice $[55,56]$. The orthotopic model using these cells has been described in detail previously [57].

\section{Cell lines and culture conditions}

Murine Py230 cells were cultured in DMEM/F-12 culture media supplemented with $10 \%$ FBS and supplemented with MITO serum extender (Corning \#355006), $1 \%$ penicillin/ streptomycin at $37^{\circ} \mathrm{C}$, in a $5 \% \mathrm{CO}_{2}$ incubator. Murine $4 \mathrm{~T} 1$ cells were cultured in RPMI-1640 culture media supplemented with $10 \%$ FBS, $1 \%$ penicillin/streptomycin at 37 ${ }^{\circ} \mathrm{C}$, in a $5 \% \mathrm{CO}_{2}$ incubator. Human MDA-MB231 breast cancer cells were cultured in DMEM supplemented with $10 \%$ FBS, $1 \%$ penicillin/streptomycin, at $37{ }^{\circ} \mathrm{C}, 5 \% \mathrm{CO}_{2}$ incubator. Cells were authenticated, and periodically tested for mycoplasma contamination.

\section{Generation of primary macrophages}

Primary human macrophages were obtained from blood samples of healthy volunteers. Magnetic bead affinity chromatography was performed to purify CD14+ monocytes as per manufacturer's instructions (Miltenyi Biotec, Woking, UK). Monocytes were incubated in RPMI media with $10 \%$ FBS and $50 \mathrm{ng} / \mathrm{mL}$ recombinant human M-CSF (Peprotech, London, UK) for 5 days post purification.

\section{Syngeneic orthotopic breast cancer models}

Two orthotopic syngeneic breast cancer models were used in these studies. In the first breast cancer model (Fig. 5), $2 \times 10^{6}$ Py230 luciferase/zsGreen labeled cells were injected into the fatpad of the third mammary gland of C57BL/6 6-8 week-old female mice. In the second model (Fig. 6),
$5 \times 10^{5} 4 \mathrm{~T} 1$ luciferase/zsGreen labelled cells were injected into the fatpad of the third mammary gland of BALB/c 6-8 week-old female mice. Tumors were measured with calipers twice a week and treatment was started when tumors started to grow and measured between 5 and $8 \mathrm{~mm}$ mean diameter. Mice were administered i.p with $\operatorname{IgG}$ isotype control antibody, paclitaxel $(100 \mathrm{mg} / \mathrm{kg})$, IGF-1/2 blocking antibody xentuzumab $(100 \mathrm{mg} / \mathrm{kg})$ [38] kindly provided by Boehringer Ingelheim, or Paclitaxel with xentuzumab, twice a week for 15 days. At humane endpoint, primary tumors and lungs were harvested, imaged using IVIS technology and tissues were either digested for FACS sorting and analysis (see details below) or formalin-fixed and paraffinembedded. Paraffin-embedded lungs were serially sectioned through the entire lung. Sections were stained with H\&E, and images were taken using a Zeiss Observer Z1 Microscope. Number of foci and total area of metastatic foci were calculated to estimate seeding and metastasis burden using ZEN imaging software.

\section{FACS sorting and analysis of tumors}

Tumor cells, TAMs, and stromal cells from murine primary breast tumors and pulmonary metastasis were analyzed and sorted using flow cytometry (FACS ARIA II, BD Bioscience, CA, USA). Single cell suspensions were prepared as previously described [22]. Cells were stained with Sytox blue viability marker (Life Technologies, Warrington, UK) and conjugated antibodies against anti-CD45-PE/ Cy7 (Biolegend, Cambridge, UK, clone 30-F11) and antiF4/80-APC (Biolegend, clone BM8) and analyzed using FACS Canto II (BD Biosciences).

\section{Gene expression}

Total RNA was isolated from FACS sorted tumor cells, TAMs and stromal cells from primary breast tumors and lung metastasis. RNA extraction and cDNA were performed as previously described [22]. Gene-specific Qiagen QuantiTect Assay primers were used for qPCR analysis and relative expression levels were normalized to gapdh expression using the formula $<2^{\wedge}-(\mathrm{Ct}$ gene of interest Ct gapdh) [58].

\section{Gene expression analysis in TCGA database}

We analyzed the Cancer Genome Atlas (TCGA) data for association between gene expression levels of $I g f l, I g f 2$, $c d 163$, and $m r c l$ and 5-year overall survival. The R/Bioconductor package 'TCGA2STAT' (v1.2) [59] was used to download the Illumina HiSeq RNAseqV2 mRNA expression and clinical data for 1097 Breast cancer samples from 
the TCGA data portal. The clinical data set was filtered down to contain only those breast cancer cases classified as "infiltrating/invasive ductal carcinoma", resulting in a reduced data set of 879 patients. For each of the candidate genes, we assessed two groups of patients; one consisting of those expressing the gene in the top $10 \%$ of expression and another containing patients expressing the gene in the bottom $10 \%$. We compared their survival using a log-rank test at 5\% significance, using the 'survival' (v2.41-3) package and plotted Kaplan-Meier curves for our 'high' and 'low' gene expression groups using 'survminer' (v0.4.0) within the 'TCGAbrowser' (v0.1.0) toolkit, reporting the $p$-value from the log-rank test (see Fig. 2c).

\section{Tissue microarrays}

A TMA containing 75 breast cancer samples from consented patients was purchased from the Liverpool Tissue Bank. This TMA did not provide information of cancer subtypes. A second TMA BR10011 containing 90 invasive breast cancer samples was purchased from US Biomax. Among these 90 invasive breast cancer samples 51 were TNBC, 13 were HR+, and 19 were HER2+. Both TMAs were subjected to immunohistochemical staining and scoring by a pathologist. Detailed information of both TMAs is provided in Supplementary Tables S1 and S2.

\section{Immunohistochemistry and immunofluorescence}

An automated DAKO PT-link (DAKO, Ely, UK) was used for deparaffinization and antigen retrieval of paraffinembedded human and mouse breast tumors and lung metastasis. Tissues were immuno-stained using the DAKO envision + system-HRP.

\section{Antibodies and procedure used for immunohistochemistry}

All primary antibodies were incubated for $2 \mathrm{~h}$ at room temperature diluted in DAKO envision kit antibody diluent: Mouse CD68 (Abcam, Cambridge, UK, ab31630 used at 1:100 after low pH retrieval). Human CD68 (DAKO, clone KP1, M081401-2), CD163 (Abcam, ab74604), PhosphoInsulin/IGF-1R (R\&D, Abingdon, UK, AF2507), phosphoinsulin receptor (Lifespan Biosciences, Nottingham, UK, LS-C177981), phospho-IGF-1R (Biorbyt, Cambridge, UK, orb97626), IGF-1 (Abcam, ab9572), IGF-2 (Abcam, ab9574), CD206 (Abcam, ab8918), dilutions and conditions used as previously described [22]. Subsequently, samples were incubated with secondary HRP-conjugated antibody (from DAKO envision kit) for $1 \mathrm{~h}$ at room temperature. Staining was developed using diamino-benzidine and counterstained with hematoxylin.
Antibodies and procedure used for Immunofluorescence on paraffin-embedded tissues

Tissue sections were incubated overnight at RT with the following primary antibodies F4/80 (Biolegend, \#123102 used at 1:200 after low pH antigen retrieval), Ki67 (Abcam ab15580 used at 1:1000 after low $\mathrm{pH}$ antigen retrieval) $\alpha$ SMA (Abcam ab7817 used at 1:100, after low $\mathrm{pH}$ antigen retrieval). Samples were washed with PBS and incubated with goat anti-rat 488 (Abcam ab96887), goat anti-rabbit 594 (Abcam ab98473) and goat anti mouse 488 (Abcam ab98637) secondary antibodies respectively all used at 1:300 and DAPI at 1:600 for $2 \mathrm{~h}$ at RT. Slides were washed with PBS, final quick wash with distilled water and mounted using DAKO fluorescent mounting media.

\section{Statistical methods}

Statistical analysis for in vitro assays and animal studies was performed using unpaired two-tailed Student's $t$-test or one-way ANOVA coupled with Bonferroni's post hoc tests, and the GraphPad Prism 5 program. All error bars indicate s.d. of $n=3$ (in vitro studies) or SEM $n=3-9$ (animal studies). Human samples were analyzed using Fisher's exact test and the Matlab version 2006b program. For animal studies the group size was calculated by power analysis using a significance level kept at 5\% and the power at $80 \%$ (according to approved corresponding Home Office Project License Application).

\section{Institutional approvals}

Human tissue studies adhered to national guidelines and were approved by the University of Liverpool. Human breast cancer tissues were either patient-consented excess material obtained from the Liverpool Tissue Bank or purchased from US Biomax. Mice were maintained under specific pathogen-free conditions and experiments were performed under an approved project licence (reference number: 403725) as according to current UK legislation, at the Biomedical Science Unit at the University of Liverpool. Blood collection studies were approved by the National Research Ethics (Research Integrity and Governance Ethics committee- Reference: RETH000807). Informed consent for blood donation was given from each volunteer based on approved institutional protocols.

We thank Dr. Ilaria Malanchi for reading the manuscript and providing critical feedback. We also thank Professor Azzam Taktak for assistance with biostatistical analysis. We thank Dr. Arthur Taylor and Professor Patricia Murray for transducing the Py 230 and 4T1 cells with zsGreen/luciferase lentivirus and Valeria Quaranta and Carolyn Rainer for assisting with FACS sorting. We thank Dr. Isabelle 
Tancioni for her technical advice with the 4T1 model. We acknowledge the Liverpool Tissue Bank for providing tissue samples, the flow cytometry/cell sorting facility, the biomedical science unit and the pre-clinical in vivo imaging facility for provision of equipment and technical assistance. We thank the patients and their families, as well as the healthy blood donors who contributed with tissue samples and blood donations to these studies.

Acknowledgements These studies were supported by a Sir Henry Dale research fellowship to Dr. Ainhoa Mielgo, jointly funded by the Wellcome Trust and the Royal Society (grant number 102521/Z/13/Z), a New Investigator research grant from the Medical Research Council to Dr. Michael Schmid (grant number MR/L000512/1) and North West Cancer Research funding. Generation of primary breast cancer cells was supported by funding provided to Dr. Lesley Ellies (K22CA118182).

Author contributions L.I. and A.S. performed most of the experiments including immunohistochemical stainings, in vivo experiments, flow cytometry, cell isolations, and qPCR. F.C. helped with the analysis and interpretation of tumor biopsies and TMAs. C.F. helped with FACS analysis. D.H. performed TCGA analysis. U.W and T.B provided with xentuzumab and technical advice for in vivo use of xentuzumab. L.G. E. generated MMTV-PYMT-derived (Py230) primary breast cancer cells. M.C.S. provided conceptual advice and helped with in vivo experiments. A.M. and L.I. designed experiments and wrote the manuscript. A.M. conceived and supervised the project. All authors helped with the analysis and interpretation of the data, the preparation of the manuscript, and approved the manuscript.

\section{Compliance with ethical standards}

Conflicts of interest The authors declare that they have no competing interests.

Open Access This article is licensed under a Creative Commons Attribution 4.0 International License, which permits use, sharing, adaptation, distribution and reproduction in any medium or format, as long as you give appropriate credit to the original author(s) and the source, provide a link to the Creative Commons license, and indicate if changes were made. The images or other third party material in this article are included in the article's Creative Commons license, unless indicated otherwise in a credit line to the material. If material is not included in the article's Creative Commons license and your intended use is not permitted by statutory regulation or exceeds the permitted use, you will need to obtain permission directly from the copyright holder. To view a copy of this license, visit http://creativecommons. org/licenses/by/4.0/.

\section{References}

1. Siegel RL, Miller KD, Jemal A. Cancer Statistics, 2017. CA: A Cancer J Clin. 2017;67(1):7-30.

2. Wahba HA, El-Hadaad HA. Current approaches in treatment of triple-negative breast cancer. Cancer Biol Med. 2015;12 (2):106-16.

3. Rakha EA, El-Sayed ME, Green AR, Lee AH, Robertson JF, Ellis IO. Prognostic markers in triple-negative breast cancer. Cancer. 2007;109(1):25-32.
4. Schneider BP, Winer EP, Foulkes WD, Garber J, Perou CM, Richardson A, et al. Triple-negative breast cancer: risk factors to potential targets. Clin Cancer Res. 2008;14(24):8010-8.

5. Bauer KR, Brown M, Cress RD, Parise CA, Caggiano V. Descriptive analysis of estrogen receptor (ER)negative, progesterone receptor (PR)-negative, and HER2-negative invasive breast cancer, the so-called triple-negative phenotype - a populationbased study from the California Cancer Registry. Cancer. 2007;109(9):1721-8.

6. Weigelt B, Peterse JL, van't Veer LJ. Breast cancer metastasis: markers and models. Nat Rev Cancer. 2005;5(8):591-602.

7. Marquette C, Nabell L. Chemotherapy-resistant metastatic breast cancer. Curr Treat Options Oncol. 2012;13(2):263-75.

8. Klemm F, Joyce JA. Microenvironmental regulation of therapeutic response in cancer. Trends Cell Biol. 2015;25(4):198-213.

9. Fantozzi A, Christofori G. Mouse models of breast cancer metastasis. Breast Cancer Res. 2006;8(4):1-11.

10. Williams CB, Yeh ES, Soloff AC. Tumor-associated macrophages: unwitting accomplices in breast cancer malignancy. NPJ Breast Cancer. 2016;2.

11. Bingle L, Brown NJ, Lewis CE. The role of tumour-associated macrophages in tumour progression: implications for new anticancer therapies. J Pathol. 2002;196(3):254-65.

12. Campbell MJ, Tonlaar NY, Garwood ER, Huo DZ, Moore DH, Khramtsov AI, et al. Proliferating macrophages associated with high grade, hormone receptor negative breast cancer and poor clinical outcome. Breast Cancer Res Treat. 2011;128(3):703-11.

13. Leek RD, Lewis CE, Whitehouse R, Greenall M, Clarke J, Harris AL. Association of macrophage infiltration with angiogenesis and prognosis in invasive breast carcinoma. Cancer Res. 1996;56 (20):4625-9.

14. Murray PJ, Wynn TA. Protective and pathogenic functions of macrophage subsets. Nat Rev Immunol. 2011;11(11):723-37.

15. Ruffell B, Affara NI, Coussens LM. Differential macrophage programming in the tumor microenvironment. Trends Immunol. 2012;33(3):119-26.

16. Sica A, Mantovani A. Macrophage plasticity and polarization: in vivo veritas. J Clin Investig. 2012;122(3):787-95.

17. Qian BZ, Zhang H, Li JF, He TF, Yeo EJ, Soong DYH, et al. FLT1 signaling in metastasis-associated macrophages activates an inflammatory signature that promotes breast cancer metastasis. $\mathrm{J}$ Exp Med. 2015;212(9):1433-48.

18. Schmid MC, Avraamides CJ, Dippold HC, Franco I, Foubert P, Ellies LG, et al. Receptor tyrosine kinases and TLR/IL1Rs unexpectedly activate myeloid cell PI $3 \mathrm{kgamma}$, a single convergent point promoting tumor inflammation and progression. Cancer Cell. 2011;19(6):715-27.

19. Nielsen SR, Quaranta V, Linford A, Emeagi P, Rainer C, Santos A, et al. Macrophage-secreted granulin supports pancreatic cancer metastasis by inducing liver fibrosis. Nat Cell Biol. 2016;18 (5):549-60.

20. Shree T, Olson OC, Elie BT, Kester JC, Garfall AL, Simpson K, et al. Macrophages and cathepsin proteases blunt chemotherapeutic response in breast cancer. Genes Dev. 2011;25 (23):2465-79.

21. DeNardo DG, Brennan DJ, Rexhepaj E, Ruffell B, Shiao SL, Madden SF, et al. Leukocyte complexity predicts breast cancer survival and functionally regulates response to chemotherapy. Cancer Discov. 2011;1(1):54-67.

22. Ireland L, Santos A, Ahmed MS, Rainer C, Nielsen SR, Quaranta $\mathrm{V}$, et al. Chemoresistance in pancreatic cancer is driven by stromaderived insulin-like growth factors. Cancer Res. 2016;76 (23):6851-63.

23. Mao Y, Keller ET, Garfield DH, Shen KW, Wang JH. Stromal cells in tumor microenvironment and breast cancer. Cancer Metastas-- Rev. 2013;32(1-2):303-15. 
24. Bussard KM, Mutkus L, Stumpf K, Gomez-Manzano C, Marini FC. Tumor-associated stromal cells as key contributors to the tumor microenvironment. Breast Cancer Res. 2016;18(1):84.

25. Olson OC, Joyce JA. Microenvironment-mediated resistance to anticancer therapies. Cell Res. 2013;23(2):179-81.

26. Quail DF, Joyce JA. Microenvironmental regulation of tumor progression and metastasis. Nat Med. 2013;19(11):1423-37.

27. Zhang YH, Moerkens M, Ramaiahgari S, de Bont H, Price L, Meerman J, et al. Elevated insulin-like growth factor 1 receptor signaling induces antiestrogen resistance through the MAPK/ERK and PI3K/Akt signaling routes. Breast Cancer Res. 2011;13(3): R52.

28. Denduluri SK, Idowu O, Wang Z, Liao Z, Yan Z, Mohammed $\mathrm{MK}$, et al. Insulin-like growth factor (IGF) signaling in tumorigenesis and the development of cancer drug resistance. Genes Dis. 2015;2(1):13-25.

29. Pollak M. Insulin and insulin-like growth factor signalling in neoplasia. Nat Rev Cancer. 2008;8(12):915-28.

30. Lu YH, Zi XL, Zhao YH, Mascarenhas D, Pollak M. Insulin-like growth factor-I receptor signaling and resistance to trastuzumab (Herceptin). J Natl Cancer Inst. 2001;93(24):1852-7.

31. Massarweh S, Osborne CK, Creighton CJ, Qin L, Tsimelzon A, Huang S, et al. Tamoxifen resistance in breast tumors is driven by growth factor receptor signaling with repression of classic estrogen receptor genomic function. Cancer Res. 2008;68(3):826-33.

32. Farabaugh SM, Boone DN, Lee AV. Role of IGF1R in breast cancer subtypes, sternness, and lineage differentiation. Front Endocrinol. 2015;6(April):59.

33. Fagan DH, Uselman RR, Sachdev D, Yee D. Acquired resistance to tamoxifen is associated with loss of the type I insulin-like growth factor receptor: implications for breast cancer treatment. Cancer Res. 2012;72(13):3372-80.

34. Quail DF, Bowman RL, Akkari L, Quick ML, Schuhmacher AJ, Huse JT, et al. The tumor microenvironment underlies acquired resistance to CSF-1R inhibition in gliomas. Science. 2016;352 (6288):aad3018.

35. Wyckoff JB, Wang Y, Lin EY, Li JF, Goswami S, Stanley ER, et al. Direct visualization of macrophage-assisted tumor cell intravasation in mammary tumors. Cancer Res. 2007;67 (6):2649-56.

36. Lin EY, Nguyen AV, Russell RG, Pollard JW. Colony-stimulating factor 1 promotes progression of mammary tumors to malignancy. J Exp Med. 2001;193(6):727-39.

37. Maglione JE, Moghanaki D, Young LJT, Manner CK, Ellies LG, Joseph SO, et al. Transgenic polyoma middle-T mice model premalignant mammary disease. Cancer Res. 2001;61 (22):8298-305.

38. Friedbichler K, Hofmann MH, Kroez M, Ostermann E, Lamche HR, Koessl C, et al. Pharmacodynamic and antineoplastic activity of BI 836845, a ffully human IGF ligand-neutralizing antibody, and mechanistic rationale for combination with rapamycin. Mol Cancer Ther. 2014;13(2):399-409.

39. Zhang XHF, Jin X, Malladi S, Zou YL, Wen YH, Brogi E, et al. Selection of bone metastasis seeds by mesenchymal signals in the primary tumor stroma. Cell. 2013;154(5):1060-73.

40. Gooch JL, Van Den Berg CL, Yee D. Insulin-like growth factor (IGF)-I rescues breast cancer cells from chemotherapy-induced cell death - proliferative and anti-apoptotic effects. Breast Cancer Res Treat. 1999;56(1):1-10.

41. Robertson JFR, Ferrero JM, Bourgeois H, Kennecke H, de Boer $\mathrm{RH}$, Jacot W, et al. Ganitumab with either exemestane or fulvestrant for postmenopausal women with advanced, hormonereceptor-positive breast cancer: a randomised, controlled, doubleblind, phase 2 trial. Lancet Oncol. 2013;14(3):228-35.
42. Ma CX, Suman VJ, Goetz M, Haluska P, Moynihan T, Nanda R, et al. A phase I trial of the IGF-1R antibody Cixutumumab in combination with temsirolimus in patients with metastatic breast cancer. Breast Cancer Res Treat. 2013;139(1):145-53.

43. Jones RL, Kim ES, Nava-Parada P, Alam S, Johnson FM, Stephens AW, et al. Phase I study of intermittent oral dosing of the insulin-like growth factor-1 and insulin receptors inhibitor OSI906 in patients with advanced solid tumors. Clin Cancer Res. 2015;21(4):693-700.

44. Gradishar WJ, Yardley DA, Layman R, Sparano JA, Chuang E, Northfelt DW, et al. Clinical and Translational results of a phase II, randomized trial of an Anti-IGF-1R (Cixutumumab) in women with breast cancer that progressed on endocrine therapy. Clin Cancer Res. 2016;22(2):301-9.

45. Guha M. Anticancer IGF1R classes take more knocks. Nat Rev Drug Discov. 2013;12(4):250.

46. Lodhia KA, Tienchaiananda P, Haluska P. Understanding the key to targeting the IGF axis in cancer: a biomarker assessment. Front Oncol. 2015;5:152.

47. Fox EM, Miller TW, Balko JM, Kuba MG, Sanchez V, Smith RA, et al. A kinome-wide screen identifies the insulin/IGF-I receptor pathway as a mechanism of escape from Hormone dependence in breast cancer. Cancer Res. 2011;71(21):6773-84.

48. Ohlund D, Handly-Santana A, Biffi G, Elyada E, Almeida AS, Ponz-Sarvise M, et al. Distinct populations of inflammatory fibroblasts and myofibroblasts in pancreatic cancer. J Exp Med. 2017;214(3):579-96.

49. Mills CD, Lenz LL, Harris RA. A Breakthrough: macrophagedirected cancer immunotherapy. Cancer Res. 2016;76(3):513-6.

50. Augsten M. Cancer-associated fibroblasts as another polarized cell type of the tumor microenvironment. Front Oncol. 2014;4:62.

51. Bronte V, Murray PJ. Understanding local macrophage phenotypes in disease: modulating macrophage function to treat cancer. Nat Med. 2015;21(2):117-9.

52. Gibby K, You WK, Kadoya K, Helgadottir H, Young LJT, Ellies LG, et al. Early vascular deficits are correlated with delayed mammary tumorigenesis in the MMTV-PyMT transgenic mouse following genetic ablation of the NG2 proteoglycan. Breast Cancer Res. 2012;14(2):R67.

53. Guy CT, Cardiff RD, Muller WJ. Induction of mammary-tumors by expression of polyomavirus middle T-oncogene- a transgenic mouse model for metastatic disease. Mol Cell Biol. 1992;12 (3):954-61.

54. Davie SA, Maglione JE, Manner CK, Young D, Cardiff RD, MacLeod CL, et al. Effects of FVB/NJ and C57B1/6J strain backgrounds on mammary tumor phenotype in inducible nitric oxide synthase deficient mice. Transgenic Res. 2007;16 (2):193-201.

55. Dexter DL, Kowalski HM, Blazar BA, Fligiel Z, Vogel R, Heppner GH. Heterogeneity of tumor-cells from a single mouse mammary-tumor. Cancer Res. 1978;38(10):3174-81.

56. Aslakson CJ, Miller FR. Selective events in the metastatic process defined by analysis of the sequential dissemination of subpopulations of a mouse mammary-tumor. Cancer Res. 1992;52 (6):1399-405.

57. Pulaski BA, Ostrand-Rosenberg S. Reduction of established spontaneous mammary carcinoma metastases following immunotherapy with major histocompatibility complex class II and B7.1 cell-based tumor vaccines. Cancer Res. 1998;58(7):1486-93.

58. Schmittgen TD, Livak KJ. Analyzing real-time PCR data by the comparative C-T method. Nat Protoc. 2008;3(6):1101-8.

59. Wan YW, Allen GI, Liu ZD. TCGA2STAT: simple TCGA data access for integrated statistical analysis in R. Bioinformatics. 2016;32(6):952-4. 